\title{
Communication
}

\section{Nocturnal Lagophthalmos and Sleep Quality in Patients with Dry Eye Disease}

\author{
Aya Takahashi ${ }^{1,2, *, \dagger}$, Kazuno Negishi $^{1, *,+}{ }^{(\mathbb{C}}$, Masahiko Ayaki ${ }^{1,3, *(\mathbb{D}}$, Miki Uchino ${ }^{1}$ \\ and Kazuo Tsubota 1,4 \\ 1 Department of Ophthalmology, Keio University School of Medicine, Tokyo160-5852, Japan; \\ uchinomiki@yahoo.co.jp (M.U.); tsubota@z3.keio.jp (K.T.) \\ 2 Department of Ophthalmology, Tokyo Dental College Ichikawa General Hospital, Chiba 272-8513, Japan \\ 3 Otake Clinic Moon View Eye Center, Kanagawa 242-0001, Japan \\ 4 Tsubota Laboratory, Inc., Tokyo 160-8582, Japan \\ * Correspondence: ayatak1126@gmail.com (A.T.); kazunonegishi@keio.jp (K.N.); \\ mayaki@olive.ocn.ne.jp (M.A.) \\ + These authors contributed equally to this work.
}

Received: 26 May 2020; Accepted: 1 July 2020; Published: 4 July 2020

\begin{abstract}
Nocturnal lagophthalmos (NL) refers to the inability to close the eyelids during sleep, which is known to affect dry eye disease (DED) symptoms and sleep quality. This study aimed to evaluate the prevalence of NL and sleep quality in DED patients. We launched a survey website to recruit 2000 Japanese. The participants were asked to answer a questionnaire about DED, sleep quality, and happiness. Participants were divided into two groups according to the presence of DED, and responses were compared between the groups. The DED group was comprised of 890 subjects ( $44 \pm 13.8$ years, 359 males) and women were predominant $(p<0.001)$. Sleep duration was significantly shorter $(p=0.008)$, sleep latency was longer $(p<0.001)$, and sleep efficacy was worse compared with the non-DED group $(p<0.001)$. Furthermore, people belonging to the DED group were more frequently working night shifts $(p<0.001)$. NL was more prevalent in the DED group $(p=0.007)$. Logistic regression analysis showed that NL correlated with younger age, symptomatic DED, and eye symptoms upon waking. The current study suggested that NL was associated with worsened DED symptoms and poor sleep quality. Preventative eye care for lagophthalmos before and during sleep may be helpful for DED and sleep quality.
\end{abstract}

Keywords: nocturnal lagophthalmos; dry eye disease; sleep quality

\section{Introduction}

Nocturnal lagophthalmos (NL) refers to the inability to close the eyelids during sleep. The involuntary closure of eyelids during sleep provides protection to the ocular globe from mechanical insults [1]. Lack of this phenomenon can cause tear film dysfunction and worsen dry eye disease (DED) symptoms. For example, the exposed corneal area often shows an inferior horizontal punctate epithelial keratitis in the morning (Figure 1). DED is a multifactorial disease of the tear film and is known to be increasing in prevalence worldwide. Its symptoms affect the activities of daily life and patients' quality of life [2-4]. The prevalence of the disease is $5-50 \%$ and tends to be higher in women and members of the Hispanic and Asian races, compared to Caucasians [5].

Although clinical ophthalmologists often encounter patients with severe inferior epithelial keratitis early in the morning, detailed symptomatology, $\mathrm{NL}$, and sleep quality have not been comprehensively evaluated. NL could be associated with symptomatic ocular surface disorders, and those conditions should be evaluated. Understanding the prevalence of NL and its implications for DED and sleep quality may provide a clinical rationale for the nighttime treatment of symptomatic patients. 
This study aimed to investigate the prevalence of NL and sleep quality in DED patients, and to determine their relationship in order to propose better eye care for DED patients with NL.

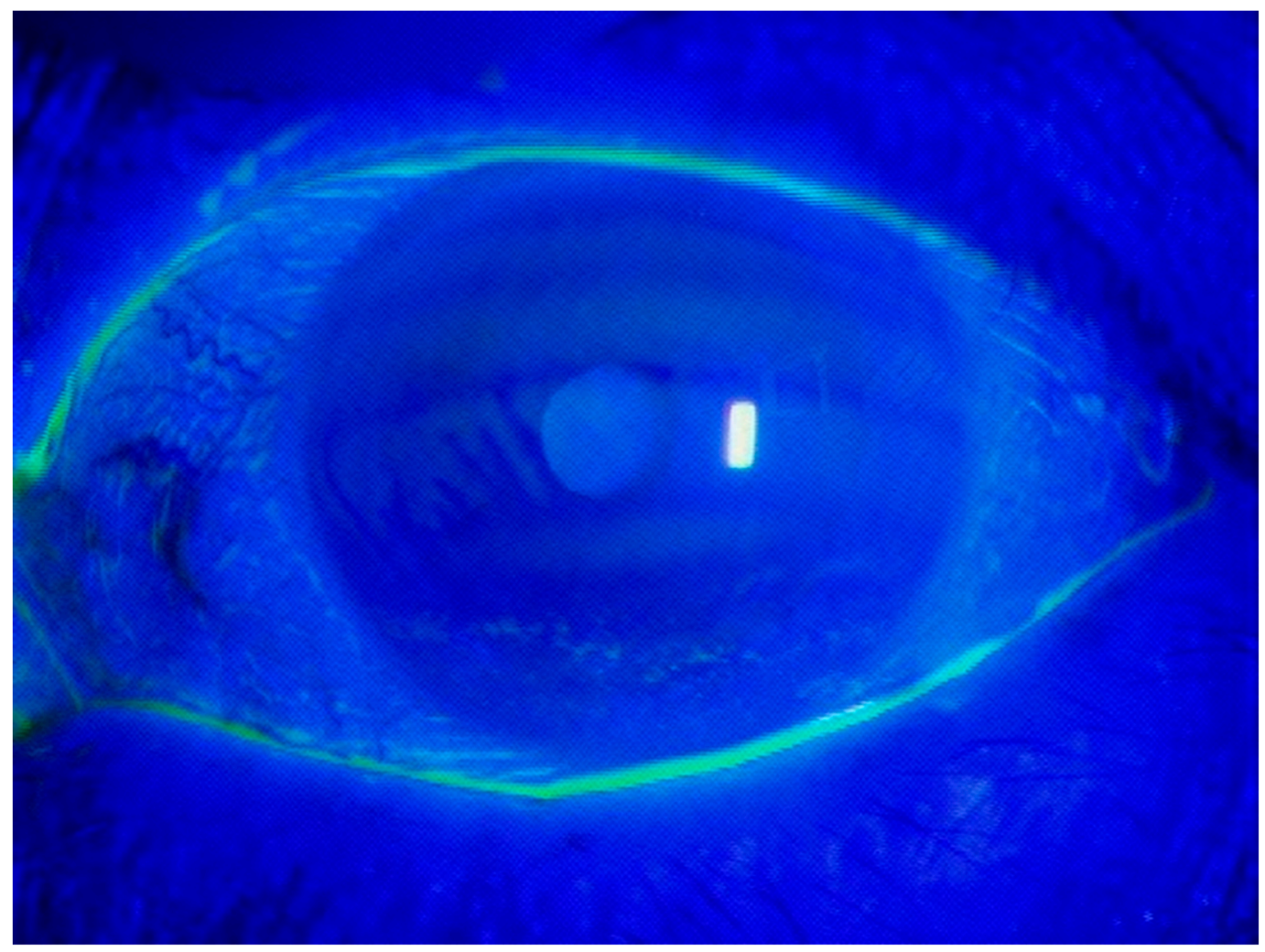

Figure 1. Clinical microscopic photograph with vital corneal staining. This patient is a 65 -year-old woman who presented at the clinic complaining of eye irritation in the morning.

\section{Methods}

\subsection{Patient Recruitment}

We hired MediProduce Incorporated (Tokyo, Japan), a company that is certified in the protection of personal information, and launched a survey website to recruit 2000 people, adjusted for age and gender. All subjects older than 20 years who used the web survey panel (Ef Press Incorporated, Tokyo, Japan) were asked to participate in this study. Among 1,700,000 panels, participants who used a visual display terminal were randomly selected and invitation mails were sent without introducing the aim of the study. The first 2000 participants who satisfied requirements were enrolled in this study. The study took place from 4 April to 13 April 2016. Participants received no money, but instead received reward points, which could be used only on the panel website, as compensation. The age groups were: twenties, thirties, forties, fifties, and sixties.

\subsection{Ethics Statements}

The research was conducted in accordance with the ethical principles of the Declaration of Helsinki and it was approved by the Institutional Review Board of Keio University (permit no. 20150399, 6 May 2015). Written informed consent, including approval for the use of information collected during the study, was obtained from the participants through the survey website.

\subsection{Questionnaire}

The participants were asked to answer 17 questions on physical information, symptoms and history of DED diagnosis, lifestyle, sleep quality, and subjective happiness (Table 1). We evaluated age, 
gender, body mass index (BMI, $\left.\mathrm{kg} / \mathrm{m}^{2}\right)$ (Q1 and 2), sleep duration (S8, 9 and 10), sleep latency (S10), sleep efficacy (the ratio of sleep duration to time in bed) (S8, 9 and 10), subjective sleep quality (S7), subjective happiness (L17), time spent outside per day (L16), frequency of working night shifts (L15), presence of NL (S11), presence of dryness of mouth (D6), and a number of DED-related symptoms (M13, answers 3 to 10). Symptoms were also analyzed in detail (M13): none (answer 1), difficulty opening eyes (3), foreign body sensation (4), eye pain (5), discharge (6), tears (7), dryness (8), and photophobia (9).

Table 1. The questionnaire used in the study.

\begin{tabular}{|c|c|}
\hline Question & Possible Answers \\
\hline 1. Height & $\mathrm{m}$ \\
\hline 2. Weight & $\mathrm{kg}$ \\
\hline \multicolumn{2}{|l|}{ Dry Eye } \\
\hline D3. "How often do you feel dryness in your eye?" & 1: constantly, 2: sometimes, 3 : rarely, $4:$ never \\
\hline $\begin{array}{l}\text { D4. "How often do you have a sensation of a foreign body in } \\
\text { your eye?" }\end{array}$ & 1: constantly, 2: sometimes, 3 : rarely, 4 : never \\
\hline D5. "Have you been diagnosed as having DED?" & 1: yes, 2: no \\
\hline D6. "Do you have a dry mouth?" & 1: constantly, 2: sometimes; 3 : rarely, 4: never \\
\hline \multicolumn{2}{|l|}{ Sleep } \\
\hline S7. "How would you rate the quality of your sleep?" & 1: great, 2: good, 3: average, 4: not good, 5: poorly \\
\hline S8. "At what time do you get up during weekdays?" & Time \\
\hline S9. "At what time do you go to bed during weekdays?" & Time \\
\hline $\begin{array}{l}\text { S10. "How long does it take you to fall asleep after you go to } \\
\text { bed?" }\end{array}$ & Duration (minutes) \\
\hline S11. "Are your eyes open during sleep?" & 1: yes, 2: no, 3: not sure \\
\hline \multicolumn{2}{|l|}{ Morning eye symptom } \\
\hline M12. "Do you wake up to eye pain during sleep?" & $\begin{array}{l}\text { 1: never, 2: once a week, 3: twice to four times a week, } \\
\text { 4: every night }\end{array}$ \\
\hline M13. "How do your eyes feel when you wake up?" & $\begin{array}{l}\text { 1: good, 2: not good, 3: have difficulty opening, } \\
\text { 4: feel foreign body sensation, } 5: \text { feel pain, } 6 \text { : eye } \\
\text { discharge, } 7: \text { lacrimation, } 8: \text { dry, } 9 \text { : sensitive to light, } \\
\text { 10: others, multiple answers allowed }\end{array}$ \\
\hline M14. "Do you take eye drops after waking or for sleeping?" & 1: at waking, 2: at sleeping, 3 : neither \\
\hline \multicolumn{2}{|l|}{ Lifestyle } \\
\hline L15. "How often do you have a night shift?" & Time per month \\
\hline L16. "How long do you spend outside during daytime?" & $\begin{array}{l}\text { 1: less than one hour, } 2: 1 \mathrm{~h}, 3: 2 \mathrm{~h}, 4: 3 \mathrm{~h}, 5: 4 \mathrm{~h}, 6: 5 \mathrm{~h} \text {, } \\
7: 6 \mathrm{~h}, 8: 7 \mathrm{~h}, 9: 8 \mathrm{~h}, 10: 9 \mathrm{~h}, 11: \text { more than } 10 \mathrm{~h}\end{array}$ \\
\hline L17. "How would you rate your happiness?" & 7-1: happiest-unhappiest \\
\hline
\end{tabular}

\subsection{Data and Statistical Analyses}

The subjects were divided into two groups according to the presence of NL. Subjects who answered 1 for question S11 were categorized as the NL (+) group, and those who answered 2 were categorized as the NL (-) group. We did not include subjects who answered 3 (not sure) in the analysis. We also compared groups with and without DED based on the answers to the validated short questionnaire (dryness and irritation of the eyes, and former diagnosis of DED [6]). We defined DED as having a previous diagnosis of DED (D5) and/or having both dryness (answer 1 or 2 on D3) and foreign body sensation (answer 1 or 2 on D4) in the eyes. Each variable was compared between the groups. Logistic regression analysis was performed using the presence of NL as a dependent valuable. 
Where appropriate, data are given as mean \pm standard deviation (SD). Given that the data were not normally distributed, we applied Student's $t$-test, the Wilcoxon signed rank test, the chi-squared test, the Mann-Whitney $U$ test, and age-and-gender-adjusted multivariate logistic regression analysis for statistical analysis in Stata, software version 16. A $p$-value of $<0.05$ was considered statistically significant.

\section{Results}

Of the 2000 subjects, 90 (4.5\%) had NL (40.5 \pm 13.8 years, 42 males) and $1174(58.7 \%)$ were without NL (44.8 \pm 13.9 years, 574 males), while 736 subjects answered that they were not sure about their NL phenomenon (44.9 \pm 13.7 years, 382 males) and 890 (44.5\%) were assigned to the DED group (44 \pm 13.8 years, 359 males).

In the NL group, subjects were significantly younger, had more frequent night shifts, and had more symptoms related to their eyes upon waking. Subjects with difficulty opening their eyes, foreign body sensation, and eye pain in the morning were likely to have NL (Table 2).

In the DED group, there were more women than men $(p<0.001)$. Sleep duration was significantly shorter $(p=0.008)$, sleep latency was longer $(p<0.001)$, and sleep efficacy was worse compared with the non-DED group $(p<0.001)$. Furthermore, awakening during sleep was more prevalent in the DED group $(p<0.001)$. NL was also more prevalent in the DED group $(p=0.007$; Table 3 , Figure 2$)$.

Logistic regression analysis produced robust results in the comparison between the two groups stratified by NL (Table 3), and it revealed that NL was significantly correlated with younger age, symptomatic DED, and more eye symptoms in the morning. Subjects with difficulty opening their eyes and eye pain were especially likely to have NL (Table 4).

Table 2. Characteristics of the study population according to nocturnal lagophthalmos (NL) category.

\begin{tabular}{|c|c|c|c|}
\hline & $\begin{array}{c}\text { NL (+) } \\
n=90(5 \%)\end{array}$ & $\begin{aligned} & \text { NL }(-) \\
n= & 1174(59 \%)\end{aligned}$ & $p$-Value \\
\hline Age (years) & $40.5 \pm 13.8$ & $44.8 \pm 13.9$ & $0.004 *$ \\
\hline Gender (male/female) & $42 / 48$ & $574 / 600$ & 0.68 \\
\hline BMI & $22.5 \pm 3.8$ & $22.2 \pm 3.7$ & 0.50 \\
\hline \multicolumn{4}{|l|}{ Sleep Parameters } \\
\hline Sleep latency (minutes) & $26.4 \pm 27.5$ & $22.3 \pm 22.1$ & 0.10 \\
\hline Sleep efficacy $(\%)$ & $93.3 \pm 6.5$ & $94.3 \pm 5.7$ & 0.13 \\
\hline Sleep duration (minutes) & $370 \pm 64$ & $377 \pm 73$ & 0.37 \\
\hline Subjective sleep quality & $2.83 \pm 1.07$ & $2.63 \pm 1.02$ & 0.07 \\
\hline Subjective happiness & $4.2 \pm 1.4$ & $4.4 \pm 1.5$ & 0.29 \\
\hline Outdoor time (hours) & $3.5 \pm 2.3$ & $3.1 \pm 2.3$ & 0.16 \\
\hline Night shift (times/month) & $1.76 \pm 5.4$ & $0.70 \pm 0.5$ & $0.002 *$ \\
\hline $\begin{array}{c}\text { Number of symptoms of eyes upon waking } \\
\text { Symptoms in Detail }\end{array}$ & \multicolumn{2}{|c|}{ Symptoms in Detail } & $<0.001$ * \\
\hline None & $39(43.3 \%)$ & $592(50.5 \%)$ & 0.189 \\
\hline Difficulty opening eyes & $13(14.4 \%)$ & 63 & $<0.001^{* *}$ \\
\hline Foreign body sensation & 18 & 95 & $<0.001^{* *}$ \\
\hline Eye pain & 6 & 29 & $0.020 * *$ \\
\hline Discharge & 22 & 276 & 0.85 \\
\hline Tears & 8 & 57 & 0.10 \\
\hline Dryness & 8 & 103 & 0.97 \\
\hline Photophobia & 3 & 98 & 0.09 \\
\hline
\end{tabular}

NL: nocturnal lagophthalmos, BMI: body mass index. ${ }^{*} p<0.05$ t-test, ${ }^{* *} p<0.05$ chi-squared test, ${ }^{* * *} p<0.05$ Mann-Whitney U test. 
Table 3. Characteristics of the study population according to dry eye disease (DED) category.

\begin{tabular}{|c|c|c|c|}
\hline & $\begin{array}{c}\text { DED (+) } \\
n=890(45 \%)\end{array}$ & $\begin{array}{c}\text { DED }(-) \\
n=1110(56 \%)\end{array}$ & $p$-Value \\
\hline Age (years) & $44.0 \pm 13.8$ & $45.2 \pm 13.9$ & 0.05 \\
\hline Gender (male/female) & $359 / 531$ & $641 / 469$ & $<0.001^{* *}$ \\
\hline BMI $\left(\mathrm{kg} / \mathrm{m}^{2}\right)$ & $22.2 \pm 4.0$ & $22.4 \pm 3.7$ & 0.26 \\
\hline \multicolumn{4}{|l|}{ Sleep Parameters } \\
\hline Sleep latency (minutes) & $25.5 \pm 24.6$ & $21.6 \pm 21.3$ & $<0.001 *$ \\
\hline Sleep efficacy $(\%)$ & $93.4 \pm 6.5$ & $94.5 \pm 5.7$ & $<0.001 *$ \\
\hline Sleep duration (minutes) & $368 \pm 74$ & $377 \pm 76$ & $0.008 *$ \\
\hline Subjective sleep quality & $2.91 \pm 1.02$ & $2.60 \pm 1.04$ & $<0.001^{* * *}$ \\
\hline Subjective happiness & $4.2 \pm 1.5$ & $4.3 \pm 1.5$ & 0.04 * \\
\hline Outdoor activity time (hours) & $3.3 \pm 2.5$ & $3.1 \pm 2.4$ & 0.05 \\
\hline Night shift (times/month) & $0.96 \pm 3.2$ & $0.63 \pm 2.9$ & $0.02 *$ \\
\hline Nocturnal lagophthalmos & $49(5.4 \%)$ & $41(3.7 \%)$ & $0.007 *$ \\
\hline Dryness of mouth & $398(44.7 \%)$ & $415(37.4 \%)$ & $0.001 * *$ \\
\hline $\begin{array}{c}\text { Number of symptoms of eyes upon waking } \\
\text { Symptoms in Detail }\end{array}$ & \multicolumn{2}{|c|}{ Symptoms in Detail } & $<0.001 *$ \\
\hline None & $225(24.7 \%)$ & $687(75.3 \%)$ & $<0.001^{* *}$ \\
\hline Difficulty opening eyes & 90 & 36 & $<0.001^{* *}$ \\
\hline Foreign body sensation & 171 & 32 & $<0.001^{* *}$ \\
\hline Eye pain & 14 & 49 & $<0.001 * *$ \\
\hline Discharge & 301 & 204 & $<0.001 * *$ \\
\hline Tears & 69 & 45 & $<0.001^{* *}$ \\
\hline Dryness & 145 & 41 & $<0.001^{* *}$ \\
\hline Photophobia & 102 & 56 & $<0.001^{* *}$ \\
\hline
\end{tabular}

DED: dry eye disease, BMI: body mass index. ${ }^{*} p<0.05 t$-test, ${ }^{* *} p<0.05$ chi-squared test, ${ }^{* * *} p<0.05$ Mann-Whitney U test

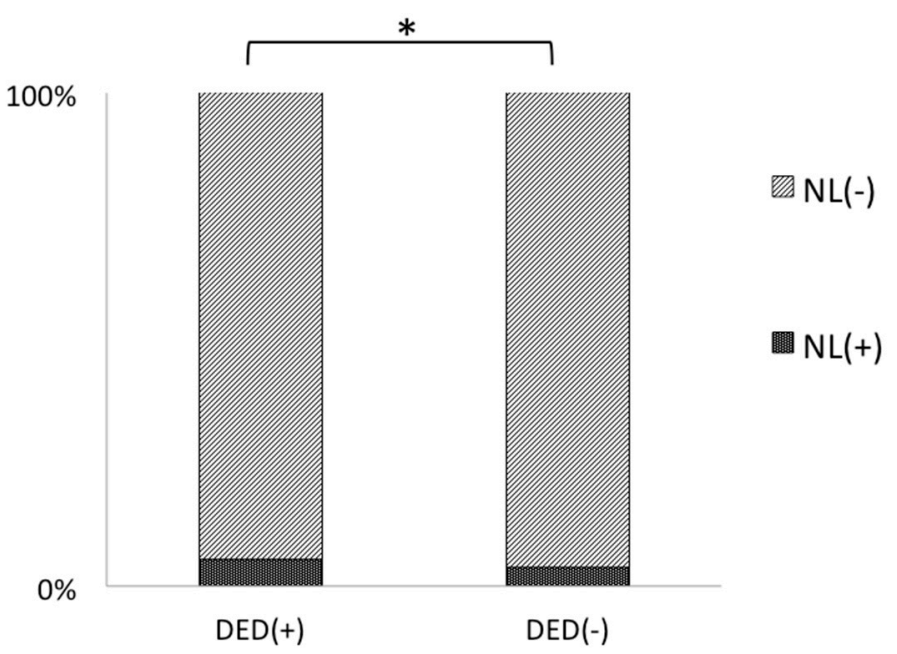

Figure 2. Nocturnal lagophthalmos was more prevalent in the group with dry eye disease than in the group without. ${ }^{*} p<0.05 t$-test.

Table 4. Risk factors for having NL.

\begin{tabular}{|c|c|c|c|}
\hline Variables & Odds Ratio & $\begin{array}{l}\text { 95\% Confidence } \\
\text { Interval }\end{array}$ & $p$-Value \\
\hline Age \# & 0.97 & $0.96-0.99$ & $0.005 *$ \\
\hline Gender (1: male, 0 : female) \# & 0.94 & $0.58-1.35$ & 0.78 \\
\hline BMI $\left(\mathrm{kg} / \mathrm{m}^{2}\right)$ & 1.03 & $0.97-1.09$ & 0.30 \\
\hline $\operatorname{DED}(1:(+), 0:(-))$ & 1.75 & $1.12-2.71$ & $0.01 *$ \\
\hline
\end{tabular}


Table 4. Cont.

\begin{tabular}{|c|c|c|c|}
\hline Variables & Odds Ratio & $\begin{array}{l}\text { 95\% Confidence } \\
\text { Interval }\end{array}$ & $p$-Value \\
\hline \multicolumn{4}{|l|}{ Sleep parameters } \\
\hline Sleep latency (minutes) & 1.00 & $0.99-1.01$ & 0.55 \\
\hline Sleep efficacy $(\%)$ & 1.00 & $0.96-1.04$ & 0.94 \\
\hline Sleep duration (minutes) & 1.00 & $0.99-1.00$ & 0.11 \\
\hline Subjective sleep quality & 1.16 & $0.94-1.43$ & 0.16 \\
\hline Subjective happiness & 1.07 & $0.92-1.26$ & 0.35 \\
\hline Outdoor time & 1.06 & $0.98-1.15$ & 0.16 \\
\hline Night shift (times/month) & 0.98 & $0.91-1.06$ & 0.62 \\
\hline Dryness of mouth $(1:(+), 0:(-))$ & 1.00 & $0.65-1.56$ & 0.99 \\
\hline $\begin{array}{c}\text { Number of symptoms of eyes upon } \\
\text { awakening }\end{array}$ & 1.23 & $1.03-1.47$ & $0.04 *$ \\
\hline \multicolumn{4}{|l|}{ Symptoms in detail } \\
\hline Difficulty opening eyes $(1:(+), 0:(-))$ & 1.99 & $1.00-3.95$ & $0.049 *$ \\
\hline Foreign body sensation $(1:(+), 0:(-))$ & 1.00 & $0.47-2.14$ & 1.00 \\
\hline Eye pain $(1:(+), 0:(-))$ & 2.71 & $1.09-6.75$ & 0.03 * \\
\hline Discharge $(1:(+), 0:(-))$ & 1.37 & $0.85-2.19$ & 0.20 \\
\hline Tears $(1:(+), 0:(-))$ & 0.82 & $0.29-2.30$ & 0.70 \\
\hline Dryness (1: $(+), 0:(-))$ & 1.73 & $0.94-3.19$ & 0.08 \\
\hline Photophobia $(1:(+), 0:(-))$ & 1.11 & $0.52-2.37$ & 0.80 \\
\hline
\end{tabular}

NL: nocturnal lagophthalmos, BMI: body mass index, DED: dry eye disease. \# Multivariate logistic regression analysis was performed adjusted for age and gender. ${ }^{*} p<0.05$.

\section{Discussion}

The current study suggested that NL was associated with DED and poor sleep. Herein, we propose the hypothesis that NL could be a hidden risk factor for DED and poor sleep (Figure 3). NL can be caused by facial nerve paralysis or facial trauma, but it is also a common phenomenon observed in otherwise-healthy individuals [1]. Reported underlying causes include alcohol consumption and the use of hypnotic medication [7]. NL was also documented as a hereditary congenital abnormality in System of Ophthalmology [8], and Sturrock et al. suggested the possibility of a genetic factor in some patients [9]. In this study, $4.5 \%$ of the subjects had a history of physiological NL, which was concordant with the previously reported prevalence in the Chinese population [10], whereas NL was found in $1.4 \%$ of the Caucasian population [11]. Mueller suggested that the phenomenon was common in Amharic people in Ethiopia due to their feature of large eyes [12].

McNab suggested that NL patients tend to be poor sleepers since the closing of the eyes during sleep may help induce and maintain sleep by reducing visual input into the cerebral cortex, as well as helping protect the ocular surface during sleep [13]. Long wavelength light transmits through closed eyelids and can lead to circadian sleep disorders ( $9 \%$ transmittance at $630 \mathrm{~nm}$ wavelength) [14]. This relationship is likely to be enhanced with partly opened eyes. Indeed, we observed a tendency of having poor subjective sleep quality in subjects with NL ( $p=0.07)$. NL may adversely affect sleep quality by 1 ) increasing the intensity of light stimuli and 2) changing the ocular surface environment, mainly affecting the tear film, which induces DED symptoms. The present results further support larger studies with a nationwide cohort to investigate the presumed effects of NL shown in the schematic presentation in Figure 3.

Tear functional change at night in patients with NL may result in a deterioration of DED symptoms. Closed-eye tears contain a functional complement system and regulatory compounds, and are activated while eyes are closed during sleep [15-17]. When eyes are open during sleep, the complement activity decreases, so we can hypothesize that the function of the regulatory system would diminish. Recent studies on DED revealed an inflammatory process and associated pathogenesis [18].

There are various ways to treat NL and its symptoms. The most effective and simple is using ophthalmic ointment at night and artificial tears or eye drops treating DED symptoms. Taping the 
eyelid closed during sleep has also proved helpful [19]. The present results showed that younger age and shift work were notable risk factors for NL. We assume that increased sympathetic activity might be related to insufficient closure of the eyelids during sleep by increasing stimulation of the Muller muscle [20]. Decreasing sympathetic activity and increasing parasympathetic activity at night, for example with hot eye masks [21], aroma therapy [22], and taking a bath [23], would help prevent NL. These countermeasures for NL could substantially improve sleep quality. The future outlook of NL treatment would include careful examination of the underlying disease, proper instruction on alcohol consumption to patients, and re-examining patients' oral medications, including hypnotic agents. Since DED and sleep disorders are possibly related to NL mutually, treatment of DED or of sleep disorders might be helpful for treating NL. For genetically associated NL, neurosurgery and oculofacial surgery may be indicated in addition to medical measures according to severity and disability.

The diagnosis of NL can be challenging because there are no changes on the eyelids during the day. When patients with certain symptoms undergo an ophthalmic examination, findings such as punctate keratoplasty and insufficient closure of eyes when they blink involuntarily can easily be ignored. This is one of the reasons that the epidemiology and effects of NL on health are not well known.

The present results were compatible with previous reports revealing that women are more likely to have DED compared to men [24] and that people with DED had poor sleep quality, especially DED-symptom-related sleep quality [25-29]. The results might provide additional evidence for a clinical association between DED and sleep, and help serve DED patients better.

We acknowledge several limitations of this study. First, the relatively low frequency of NL may be a limitation on analyzing the data. Nevertheless, this study successfully captured the close relationship between NL and DED to propose new insights into the diagnosis and management of DED. Second, clinical data would confirm the current results, since DED diagnosis relied on self-reported questionnaires, although we used a questionnaire that had been suitably validated to evaluate the prevalence of DED. Another limitation of using a self-administered questionnaire, which might have introduced biases, pertained to possible misunderstanding regarding the questions on medication use and the subjects' health status. This study only includes a self-screening evaluation, which might be a limitation. However, a larger sample size should overcome this limitation, and this study design may be sufficient to demonstrate the association of DED, sleep quality, and NL. The current study showed a correlation between NL and sleep quality. For further elucidating a causal relationship, we suggest a systematic evaluation, including ophthalmic examination and physical evaluation.

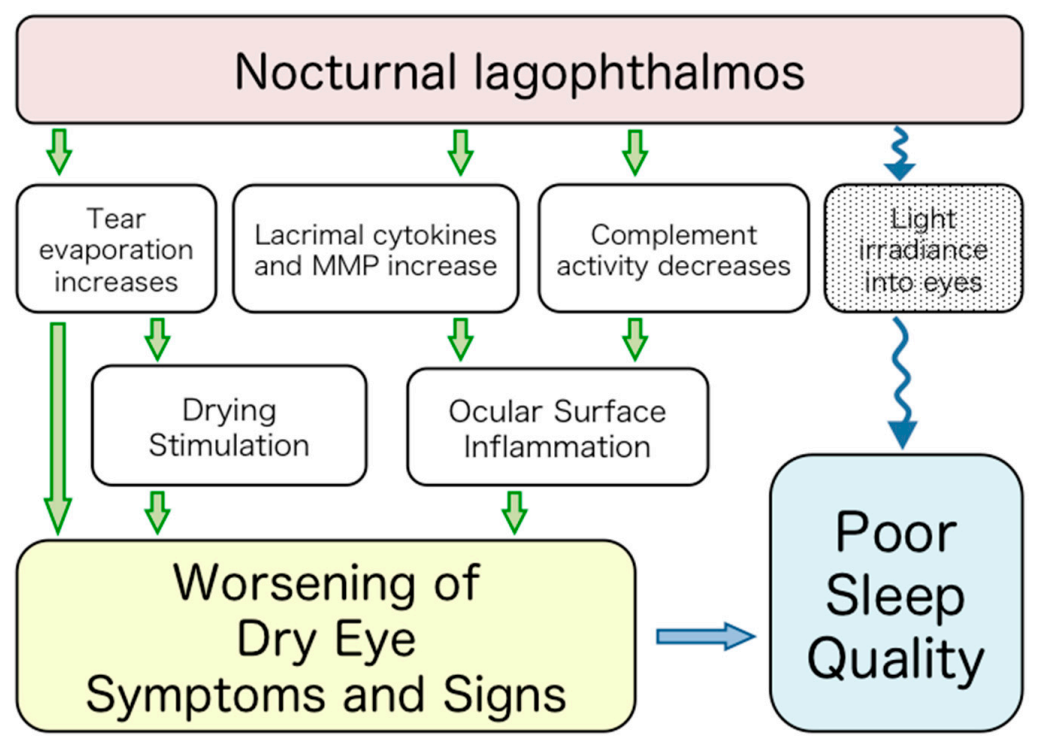

Figure 3. Hypothesis of the effects of nocturnal lagophthalmos on dry eye disease and sleep quality. 


\section{Conclusions}

The current study suggests that NL is associated with DED and sleep quality. Managing lagophthalmos and related symptoms may help improve DED and sleep quality. Further studies would contribute to establishing etiology-based classification, pathology, preventive measures, and effective treatments for NL.

Author Contributions: Conceptualization, M.A.; data curation, A.T. and M.A.; formal analysis, A.T.; investigation, A.T. and M.A.; methodology, A.T. and M.A.; project administration, M.A.; resources, M.A.; software, A.T.; supervision, K.N. and K.T.; validation, A.T., M.A., and M.U.; visualization, A.T.; writing-original draft, A.T.; writing-review and editing, A.T., K.N., M.A., M.U. and K.T. All authors have read and agreed to the published version of the manuscript.

Funding: There was no funding for this study.

Conflicts of Interest: The authors declare no conflict of interest.

\section{References}

1. Tsai, S.H.; Yeh, S.I.; Chen, L.J.; Wu, C.H.; Liao, S.L. Nocturnal Lagophthalmos. Int. J. Gerontol. 2009, 3, 89-95. [CrossRef]

2. Uchino, M.; Schaumberg, D.A. Dry Eye Disease: Impact on Quality of Life and Vision. Curr. Ophthalmol. Rep. 2013, 1, 51-57. [CrossRef] [PubMed]

3. Paulsen, A.J.; Cruickshanks, K.J.; Fischer, M.E.; Huang, G.H.; Klein, B.E.; Klein, R.; Dalton, D.S. Dry eye in the beaver dam offspring study: Prevalence, risk factors, and health-related quality of life. Am. J. Ophthalmol. 2014, 157, 799-806. [CrossRef] [PubMed]

4. Matossian, C.; McDonald, M.; Donaldson, K.E.; Nichols, K.K.; MacIver, S.; Gupta, P.K. Dry Eye Disease: Consideration for Women's Health. J. Women's Health 2019, 28, 502-514. [CrossRef]

5. Clayton, J.A.; Albeitz, J.; Begley, C.; Caffery, B.; Nichols, K.; Schaumberg, D.A.; Schein, O. The epidemiology of DED disease: Report of the Epidemiology Subcommittee of the International DED WorkShop. Ocul. Surf. 2007, 5, 93-107.

6. Gulati, A.; Sullivan, R.; Buring, J.E.; Sullivan, D.A.; Dana, R.; Schaumberg, D.A. Validation and Repeatability of a Short Questionnaire for Dry Eye Syndrome. Am. J. Ophthalmol. 2006, 142, 125-131. [CrossRef]

7. Lyons, C.J.; McNab, A.A. Symptomatic nocturnal lagophthalmos. Aust. N. Z. J. Ophthalmol. 1990, 18, $393-396$. [CrossRef]

8. Duke-Elder, S. System of Ophthalmology; Kimpton, H.: London, UK, 1964; p. 887.

9. Sturrock, G.D. Nocturnal lagophthalmos and recurrent erosion. Br. J. Ophthalmol. 1976, 60, 97-103. [CrossRef]

10. Fuchs, A.; Wu, F.C. Sleep with half-open eyes, physiologic lagophthalmus. Am. J. Ophthalmol. 1948, 31, 717-720. [CrossRef]

11. Howitt, D.A.; Goldstein, J.H. Physiologic lagophthalmos. Am. J. Ophthalmol. 1969, 68, 355. [CrossRef]

12. Mueller, F.O. Lagophthalmos during sleep. Br. J. Ophthalmol. 1967, 51, 246-248. [CrossRef] [PubMed]

13. McNab, A.A. The eye and sleep. Clin. Exp. Ophthalmol. 2005, 33, 117-125. [CrossRef] [PubMed]

14. Bierman, A.; Figueiro, M.G.; Rea, M.S. Measuring and predicting eyelid spectral transmittance. J. Biomed. Opt. 2011, 16, 067011. [CrossRef] [PubMed]

15. Willcox, M.D.; Morris, C.A.; Thakur, A.; Sack, R.A.; Wickson, J.; Boey, W. Complement and complement regulatory proteins in human tears. Investig. Ophthalmol. Vis. Sci. 1997, 38, 1-8.

16. Sack, R.A.; Beaton, A.; Sathe, S.; Morris, C.; Willcox, M.; Bogart, B. Towards a closed eye model of the pre-ocular tear layer. Prog. Retinal Eye Res. 2000, 19, 649-668. [CrossRef]

17. Sack, R.A.; Conradi, L.; Krumholz, D.; Beaton, A.; Sathe, S.; Morris, C. Membrane array characterization of 80 chemokines, cytokines, and growth factors in open- and closed-eye tears: Angiogenin and other defense system constituents. Investig. Ophthalmol. Vis. Sci. 2005, 46, 1228-1238. [CrossRef] [PubMed]

18. Yamaguchi, T. Inflammatory Response in Dry Eye. Investig. Ophthalmol. Vis. Sci. 2018, 59, 192-199. [CrossRef] [PubMed]

19. Katz, J.; Kaufman, H.E. Corneal exposure during sleep (nocturnal lagophthalmos). Arch. Ophthalmol. (Chicago IL. 1960) 1977, 95, 449-453. [CrossRef]

20. Small, R.G.; Fransen, S.R.; Adams, R.; Owen, W.L.; Taylor, R.B., 3rd. The effect of phenylephrine on Müller muscle. A blepharogram study of eyelid motion. Ophthalmolog 1995, 102, 599-606. [CrossRef] 
21. Takamoto, K.; Hori, E.; Urakawa, S.; Katayama, M.; Nagashima, Y.; Yada, Y.; Ono, T.; Nishijo, H. Thermotherapy to the facial region in and around the eyelids altered prefrontal hemodynamic responses and autonomic nervous activity during mental arithmetic. Psychophysiology 2013, 50, 35-47. [CrossRef]

22. Tanida, M.; Niijima, A.; Shen, J.; Nakamura, T.; Nagai, K. Olfactory stimulation with scent of lavender oil affects autonomic neurotransmission and blood pressure in rats. Neurosci. Lett. 2006, 398, 155-160. [CrossRef] [PubMed]

23. Ely, B.R.; Francisco, M.A.; Halliwill, J.R.; Bryan, S.D.; Comrada, L.N.; Larson, E.A.; Brunt, V.E.; Minson, C.T. Heat therapy reduces sympathetic activity and improves cardiovascular risk profile in obese women with polycystic ovary syndrome. Am. J. Physiol. Regul. Integr. Comp. Physiol. 2019, 317, 630-640. [CrossRef]

24. Farrand, K.F.; Fridman, M.; Stillman, I.; Schaumberg, D.A. Prevalence of Diagnosed Dry Eye Disease in the United States Among Adults Aged 18 Years and Older. Am. J. Ophthalmol. 2017, 182, 90-98. [CrossRef] [PubMed]

25. Ayaki, M.; Kawashima, M.; Negishi, K.; Kishimoto, T.; Mimura, M.; Tsubota, K. Sleep and mood disorders in dry eye disease and allied irritating ocular diseases. Sci. Rep. 2016, 6, 22480. [CrossRef] [PubMed]

26. Ayaki, M.; Tsubota, K.; Kawashima, M.; Kishimoto, T.; Mimura, M.; Negishi, K. Sleep Disorders are a Prevalent and Serious Comorbidity in Dry Eye. Investig. Ophthalmol. Vis. Sci. 2018, 59, 143-150. [CrossRef]

27. Ayaki, M.; Kawashima, M.; Negishi, K.; Tsubota, K. High prevalence of sleep and mood disorders in dry eye patients: Survey of 1,000 eye clinic visitors. Neuropsychiatr. Dis. Treat. 2015, 11, 889-894. [CrossRef]

28. Kawashima, M.; Uchino, M.; Yokoi, N.; Uchino, Y.; Dogru, M.; Komuro, A.; Sonomura, Y.; Kato, H.; Kinoshita, S.; Tsubota, K. The association of sleep quality with dry eye disease: The Osaka study. Clinic. Ophthalmol. (Auckl. N. Z.) 2016, 10, 1015-1021. [CrossRef]

29. Yu, X.; Guo, H.; Liu, X.; Wang, G.; Min, Y.; Chen, S.S.; Han, S.S.; Chang, R.T.; Zhao, X.; Hsing, A.; et al. Dry eye and sleep quality: A large community-based study in Hangzhou. Sleep 2019, 42, 160. [CrossRef]

(C) 2020 by the authors. Licensee MDPI, Basel, Switzerland. This article is an open access article distributed under the terms and conditions of the Creative Commons Attribution (CC BY) license (http://creativecommons.org/licenses/by/4.0/). 